\title{
Development of Risk Index of Uninterrupted Traffic Flow According to the Occurrence of Fog
}

\author{
Soullam Kim*, Sung Han Lim \\ Korea Institute of Civil Engineering and Building Technology, South Korea \\ Email: *soulkim@kict.re.kr
}

How to cite this paper: Kim, S. and Lim, S.H. (2018) Development of Risk Index of Uninterrupted Traffic Flow According to the Occurrence of Fog. World Journal of Engineering and Technology, 6, 519-531. https://doi.org/10.4236/wjet.2018.63031

Received: May 10, 2018

Accepted: June 8, 2018

Published: June 11, 2018

Copyright $\odot 2018$ by authors and Scientific Research Publishing Inc. This work is licensed under the Creative Commons Attribution International License (CC BY 4.0).

http://creativecommons.org/licenses/by/4.0/

(c) (i) Open Access

\begin{abstract}
The driver's visibility is degraded when weather conditions deteriorate, which affects the traffic flow and induces traffic congestion or accidents. In particular, traffic accidents can be led to chain reaction collisions, with high rate of fatality, when fog occurs in contrast to other weather factors that may restrict visibility. For the development of a traffic risk index, a deviation of the vehicle's speed was set for the traffic risk index by referring to previous study results. In addition, factors that affected the deviation in a vehicle's speed were selected as independent variables based on the traffic flow analysis during occurrences of fog. The visible distance, traffic volume, and speed were selected as the independent variables to estimate the optimal parameters in the regression model. The traffic risk index model during occurrences of fog proposed in this study is an exponential model, with the visible distance and the traffic volume defined as independent variables. According to the study model, traffic risk increased as the visible distance decreased and the traffic volume was lower. Thus, the visible distance that can affect traffic flow during occurrences of fog can be determined in the future based on the results of this study. The study results will be expected to contribute to not only traffic safety improvements, but also the facilitation of traffic flow as drivers and traffic operation managers intuitively recognize the level of risk.
\end{abstract}

\section{Keywords}

Fog, Visibility, Traffic Flow, Speed-Flow Relationship, Risk Index

\section{Introduction}

Bad weather conditions are known to interrupt traffic flow and increase the risk of traffic accidents, as they can affect the driving environment negatively. Along with the various weather factors such as rainfalls and snow, fog is directly related to the visibility of drivers, therefore, these conditions present a higher risk com- 
pared to the other weather factors that do not restrict visibility. The results of the statistical analysis on traffic accidents in Korea in 2014 showed that $0.5 \%$ of all traffic accidents occurred under foggy conditions, which was appeared to be a relatively low rate when compared to other conditions such as $80.3 \%$ on sunny days, $9.6 \%$ on rainy days, and $1.1 \%$ on snowy days, but the fatality rate of the traffic accidents on foggy days was $6.9 \%$, which was the highest fatality rate as compared to $1.9 \%$ on sunny days, $2.5 \%$ on rainy days, and $2.5 \%$ on snowy days [1]. In fact, traffic accidents during occurrences of fog have led to large scale traffic accidents in Korea, as exemplified in 29 vehicle chain reactions collisions on the Seohae Bridge on October 3, 2006, the 104 vehicle chain reactions collisions on the Cheonan-Nonsan Expressway on December 24, 2011, the 43 vehicle chain reactions collisions on the Jungang Expressway on January 15, 2015, and the 106 vehicle chain reactions collisions on the Youngjong Grand Bridge on February 11, 2015 [2] [3] [4] [5]. Thus, it is necessary to prevent traffic accidents and minimize traffic congestion through the efficient management on traffic flow due to occurrences of fog. Previously, a large number of studies have been conducted to analyze traffic characteristics during occurrences of fog and to identify the relationship between fog and traffic characteristics. Most of the studies concentrated on the analysis of traffic speed variations due to the reduced visible distances [6] [7] [8], and some other studies have analyzed the traffic volume, the following distance to the car in front, and the speed as indicators of traffic accidents [9] [10] [11] [12]. Most study results showed that as the visible distance decreased, the speed also decreased, and in particular, the reduction in speed became larger when the visible distance became less than $200 \mathrm{~m}$ [6]-[12]. The above study results revealed that an index that can represent the level of risk quantitatively, due to fog, is needed for efficient traffic management, but few studies have been conducted concerning that issue. Jo [13] defined fog that disrupts driving safety and induces traffic accidents by degrading the visible distance on the road as road risk fog, and developed the risk of fog occurrence index, which is based on the radiation fog potential index model proposed by Chandler [14]. The number of foggy days, the fog start and dissipation times, and the characteristics of the distribution of visible distances were analyzed using fog data from 72 nationwide manned observatories courtesy of the Korea Meteorological Administration (KMA) from 1998 to 2000 [15]. The hazardous fog index (HFI) was defined by using the weighted product of the number of foggy days whose visible distance was less than $500 \mathrm{~m}$, the duration time, and the visible distance to ascertain the level of fog risk. The number of foggy days, the fog start and dissipation times, and the characteristics of the distribution of visible distances were analyzed using fog data from 72 nationwide manned observatories courtesy of the Korea Meteorological Administration (KMA) from 1998 to 2000. Lim [16] analyzed that the fatality rates of traffic accidents that occurred from 1990 until 2003 during occurrences of fog and found the highest fatality rate in regard to weather conditions was 12.8 person/100 cases due to fog, which was much higher than that of other weather conditions. In addition, if the visible 
distance was less than $200 \mathrm{~m}$, the number of traffic accidents and the severity of these accidents rapidly increased, and speeds of $40 \mathrm{~km} / \mathrm{h}$ and $60 \mathrm{~km} / \mathrm{h}$ were suggested when the visible distance was less than $100 \mathrm{~m}$, and between 100 and 200 $\mathrm{m}$, respectively, in consideration to the minimum stopping distance and the degraded visibility. Park et al. [17] analyzed the factors of traffic accidents considering weather conditions and road alignment. In analyzing the data concerning traffic accidents that occurred on national expressways from 2005 to 2008, concerning weather condition, 500 cases (100 cases each for snowy, sunny, rainy, foggy, and cloudy conditions) were randomly selected, and the data concerning the geometric structure of the road section characteristics for each accident location were employed. A discriminant analysis was conducted using the analyzed data. An impact indicator was created based on the analysis result. A concrete road surface and a downhill gradient of $3 \%$ or steeper were selected as coefficient values for the classification function as the impact indicator of the geometric structure. In the case of concrete road surfaces with a downhill gradient of $3 \%$ or steeper, the analysis produced a 0.61 during fog occurrences, which was the most dangerous weather condition when compared to other weather conditions. Park et al. [18] determined the safety of the traffic flow using speed data of the VDS and the visible distance on the Seojong Bridge. In addition, a risk level was proposed, and a speed and visible distance at $t+1$ time were predicted using the K-Nearest Neighbor (K-NN) model. For risk determination (hazardous spacing index, HSi), if the visible distance is longer than the stopping distance based on a day that had a $100 \mathrm{~m}$ to $500 \mathrm{~m}$ visible distance, it was considered to be a safe traffic flow, otherwise it was considered as a dangerous traffic flow.

The results of the previous studies showed that it was necessary to employ a five-min or shorter period between data points in order to analyze the relationship between traffic characteristics and fog that change in real time, but few studies have been conducted on five-min or shorter period of data, and most of these studies were limited to the analysis on the relationship between fog and speed. Thus, few studies have been conducted on the determination of the traffic flow type considering the traffic volume, speed, and density. In addition, although a road risk fog occurrence index, a safety speed, and a safety determination index were developed in previous studies, most had limitations that did not fully reflect the traffic flow, for example some only considered the minimum stopping and visibility distance.

Thus, this study aimed to develop a traffic risk index based on the analysis of changes in traffic characteristics according to a visible distance level during occurrences of fog to improve traffic safety and the efficiency of traffic management.

\section{Selection of Test Section and Data Collection}

This study targeted only an area of uninterrupted traffic flow to exclude the effect of factors other than fog, such as traffic signals and pedestrians as much as possible. In addition, a road section where fog is generated frequently was tar- 
geted. A section of National Highway No. 77 from the Gusan Interchange to the Isanpo Interchange was selected as the analysis location. The location diagram in the analysis target section is shown in Figure 1.

In the target section, two vehicle detection systems (VDS) and a sensor for visible distance were installed. The VDS was located near the middle point of the target section, and the VDS and visible distance sensors were located approximately within $100 \mathrm{~m}$ of each other. This study utilized a single VDS in the upstream portion of the road. Table 1 presents the basic information for the target section.

The data was collected from Jan. 1 to May 31 in 2015, and the traffic data was obtained from the upstream VDS. The traffic volume and speed information were measured every 30 seconds. For fog data, the data from the visible distance sensor was employed and the visibility information was collected minute. In addition, the study section had an uninterrupted flow without entries or exits, so a constant traffic flow was assumed. The density was calculated and utilized via the formula $\mathrm{Q}=\mathrm{UK}$, using the traffic volume and speed data.

This study selected foggy days as the priority for the collection data to analyze changes in traffic characteristics according to the occurrence of fog. The definition of the fog for this study was fog whose horizontal visible distance was 1,000 $\mathrm{m}$ or lower according to the KMA. The fog frequency and duration were considered on the selected foggy days. As for the fog frequency, the visible distance proposed in previous studies, and the minimum stopping distances using the speed limit of the road section were considered. As for the fog duration, the days of continued fog for more than one hour were considered, assuming that traffic characteristics would change over the duration time, even if the visible distance remained the same.

The speed limit on the section of road was $90 \mathrm{~km} / \mathrm{h}$, and the mean driving speed in the road was 80 to $85 \mathrm{~km} / \mathrm{h}$ [19]. In the national guideline, the recommended minimum stopping distance is $155 \mathrm{~m}$ at $85 \mathrm{~km} / \mathrm{h}$ [20]. In addition, previous studies mentioned that traffic characteristics changed when the visible distance was less than $200 \mathrm{~m} \mathrm{[6]} \mathrm{[9]} \mathrm{[16].}$

Thus, this study selected days when the fog had caused $200 \mathrm{~m}$ or shorter visibilities based on both of the minimum stopping distance and the visible distance in previous studies, and the fog duration was more than one hour. Table 2 presents the fog frequencies.

Fog occurs most in February and March. The frequency of fog whose visibility is $200 \mathrm{~m}$ or shorter is higher than that of other visibilities. Thus, the study analysis period was set to days whose fog's visibility level was $200 \mathrm{~m}$ or shorter and the fog duration was more than one hour. The days used in the analysis were February 11, March 27, and March 30, in 2015. The dates one week before and one week after the study days, when no fog occurred, were used to compare the traffic characteristics between foggy and non-foggy days. Table 3 presents the selected analysis days. 
Table 1. Definition of variables.

\begin{tabular}{cc}
\hline Study area/distance & Content \\
\hline $\begin{array}{c}\text { Number of lanes } \\
\text { (one way) }\end{array}$ & $\begin{array}{c}\text { Jayuro Gusan IC-Isanpo IC, } \\
\text { approximately } 4.9 \mathrm{~km}\end{array}$ \\
$\begin{array}{c}\text { Upstream } \\
\text { traffic volume } \\
\text { (vehicle/day) } \\
\text { Speed limit }\end{array}$ & 4 \\
ICs & 50,342 \\
\hline
\end{tabular}

Table 2. Definition of variables.

\begin{tabular}{cccccccc}
\hline \multirow{2}{*}{$\begin{array}{c}\text { Frequency of } \\
\text { fog (min) }\end{array}$} & $1000-500$ & $500-400$ & $400-300$ & $300-200$ & $200-100$ & Below 100 & Total \\
\cline { 2 - 8 } & 348 & 21 & 6 & 0 & 0 & 0 & 375 \\
Jan. & 436 & 99 & 71 & 45 & 68 & 207 & 926 \\
Feb. & 154 & 26 & 26 & 63 & 363 & 28 & 660 \\
Mar. & 27 & 0 & 0 & 0 & 0 & 0 & 27 \\
Apr. & 52 & 17 & 22 & 84 & 156 & 0 & 331 \\
May & & & & & &
\end{tabular}

Table 3. Analysis periods.

\begin{tabular}{cc}
\hline With fog & Without fog \\
\hline Feb. 11, 2015 (Wed.) & Feb. 4, 2015 (Wed.) \\
Mar. 27, 2015 (Fri.) & Apr. 3, 2015 (Fri.) \\
Mar. 30, 2015 (Mon.) & Apr. 6, 2015 (Mon.) \\
\hline
\end{tabular}

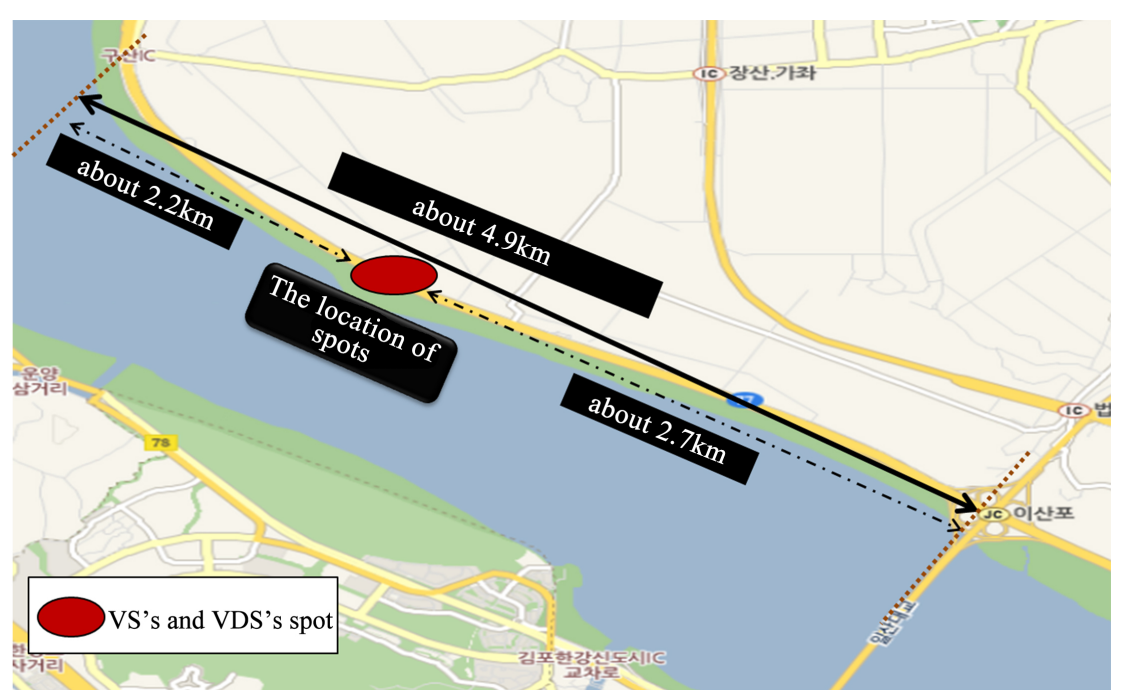

Figure 1. Study area. 


\section{Analysis on Traffic Characteristics Due to the Occurrence of Fog}

The traffic flow model shows significant changes under various taking into account variables such as drivers, weather, and road geometry. This study took only the effects of foggy conditions on traffic flow into consideration and did not consider the other variables. This study aimed to determine the level of visible distance that affected traffic flow by analyzing the relationship of speed and traffic volume according to the visible distance. For the traffic volume calculation, a one-hour traffic flow rate was employed in which the traffic volume per vehicle type is converted to the passenger car unit ( $\mathrm{pcu}$ ), using the daily traffic volume and passenger car equivalent for the study section [21].

Figure 2 shows the analyzed results with the speed-traffic volume model based on the data from the foggy days. Figures from February 11 fog the occurrence identified the upstream traffic flow at $200-1800 \mathrm{pcu} / \mathrm{h} / \mathrm{ln}$ and that had decreased to $100-700 \mathrm{pcu} / \mathrm{h} / \mathrm{ln}$ in the case of the downstream traffic flow. A significant difference in the speed-traffic flow relationship between foggy and non-foggy days was revealed at the level of $800-1800 \mathrm{pcu} / \mathrm{h} / \mathrm{ln}$ traffic flow in the upstream case and $200-600 \mathrm{pcu} / \mathrm{h} / \mathrm{ln}$ in the downstream case; these results reveal an occurrence of fog, whose visible distance was less than $200 \mathrm{~m}$. A rapid decrease in speed was found when the driving was less than $200 \mathrm{~m}$ due to fog. From the figures from March 27, an occurrence of fog identified the upstream traffic flow was $0-1000 \mathrm{pcu} / \mathrm{h} / \mathrm{ln}$ decreasing to $0-350 \mathrm{pcu} / \mathrm{h} / \mathrm{ln}$ in the downstream case. A significant difference in speed-traffic flow relationship between foggy and non-foggy days was revealed at the level of $0-400 \mathrm{pcu} / \mathrm{h} / \mathrm{ln}$ traffic flow, revealing an occurrence of fog whose visible distance was less than $200 \mathrm{~m}$. Considering the fog occurrence in the early morning of March 27, the traffic flow was significantly different between foggy and non-foggy days when the traffic flow was low. From the figures from March 30, an occurrence of fog was identified when the traffic flow was $0-1800 \mathrm{pcu} / \mathrm{h} / \mathrm{ln}$ in the upstream case and 0 - $600 \mathrm{pcu} / \mathrm{h} / \mathrm{ln}$ in the downstream case. A significant difference in the speed-traffic flow relationship between foggy and non-foggy days was revealed at the level of $0-400 \mathrm{pcu} / \mathrm{h} / \mathrm{ln}$ traffic flow, revealing an occurrence of fog whose visible distance was less than $200 \mathrm{~m}$.

\section{Method of Development of Risk Index and Results}

This study estimated parameters using a regression model and selected a model equation whose explanatory power was the highest among the models to derive a risk index. The used regression model was largely divided into linear and non-linear models based on the Greenshildes model, which was a linear model, and the Greenberg model, which was a non-linear model, among the traffic flow models. The non-linear model was then divided into exponential and natural logarithm models. This was based on study results of Lee \& Lim [22] in which a regression analysis was conducted to represent the causal relationship between 

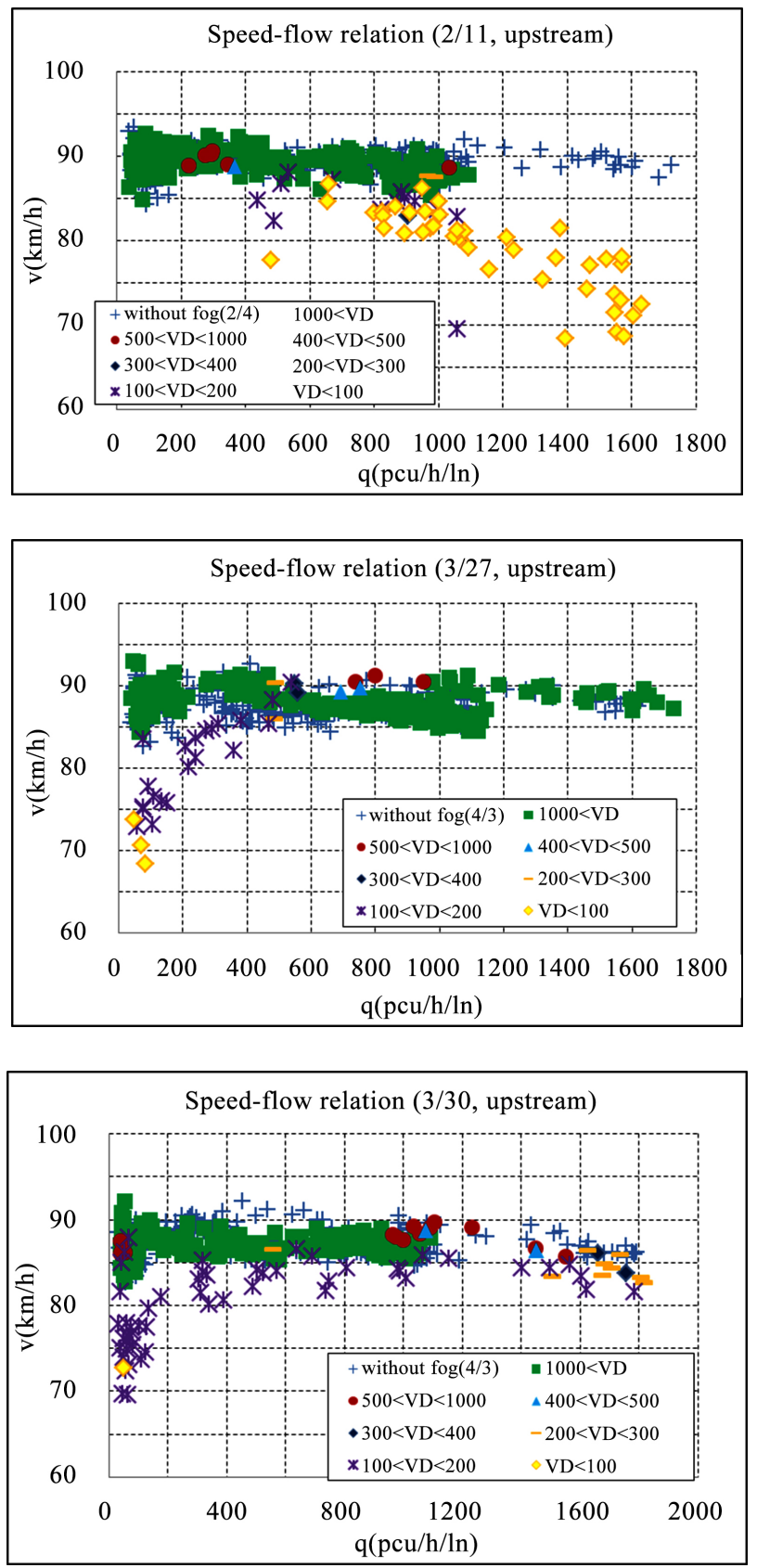

Figure 2. Speed flow relation under foggy conditions.

dependent and independent variables when both the dependent and independent variables were interval and ratio scales, that is, quantitative scales.

In addition, a deviation for vehicle speed was set as a level of risk to derive the traffic risk index. This was based on the previous study results, in which traffic accidents increased when the deviation in speed increased [23] [24] [25]. Thus, a level of risk that was a dependent variable, the deviation in speed, was selected as the coefficient of variation. Since the coefficient of variation reflected the standard deviation and means, deviations at different times can be objectively compared. 


\subsection{Variable Setup and Parameter Estimation}

As for the independent variables, factors that affected the deviation in speed were selected through the analysis on the changes in traffic flow. First, a visible distance that affected the traffic risk level due to an occurrence of fog was selected as the basic variable. In addition, the traffic volume, density, and speed were additionally selected as independent variables, assuming that deviation in speed would be affected by the independent variables. However, since a multicollinearity problem occurs in the case of the traffic volume and density, as the variance inflation factor (VIF) was more than 10 , only the traffic volume was selected as an independent variable. Through the above process, the independent variable included in the model equation were divided into four cases to propose the risk index model, based on the model with the highest explanatory power. The model with the four cases, which are divided by independent variable, is presented in Table 4.

The parameter estimation results of the regression model are presented in $\mathrm{Ta}$ ble 5. The risk index model, in which the coefficient values of all variables are statistically significant, and the explanatory power is the highest, is proposed. The analysis results showed that the linear and the exponential models with variables of visible distance and traffic volume and the natural logarithm model with a variable of visible distance were statistically significant models. Among those models, the exponential model showed the highest explanatory power.

The explanatory power in the exponential model was higher than that of the linear model. The explanatory power of the model equation was the highest when all variables: visible distance, traffic volume, and speed were used, but the coefficient values of the variables excluding traffic volume were 0.05 or higher, which led them not to be significant. When the visible distance and speed were used as variables, all coefficient values became insignificant, and the model using only the visible distance showed that the coefficient value was significant, but had lower explanatory power.

Thus, this study aimed to propose a risk index model, in which the coefficient values of all variables were statistically significant and the explanatory power was the highest.

\subsection{Establishment of the Traffic Risk Index Model}

The final proposed traffic index model equation in this study is presented in Equation (5-1).

Table 4. Selection of variables in the traffic risk index model.

\begin{tabular}{cc}
\hline Dependent variable $(\mathrm{y})$ & Independent variable $(\mathrm{x})$ \\
\hline $\begin{array}{c}\text { Coefficient of variation } \\
\text { (risk level) }\end{array}$ & Visible distance $\left(\mathrm{x}_{1}\right)$, traffic volume $\left(\mathrm{x}_{2}\right)$ \\
Visible distance $\left(\mathrm{x}_{1}\right)$, speed $\left(\mathrm{x}_{3}\right)$ \\
Visible distance $\left(\mathrm{x}_{1}\right)$
\end{tabular}


Table 5. Estimation results of regression model parameters.

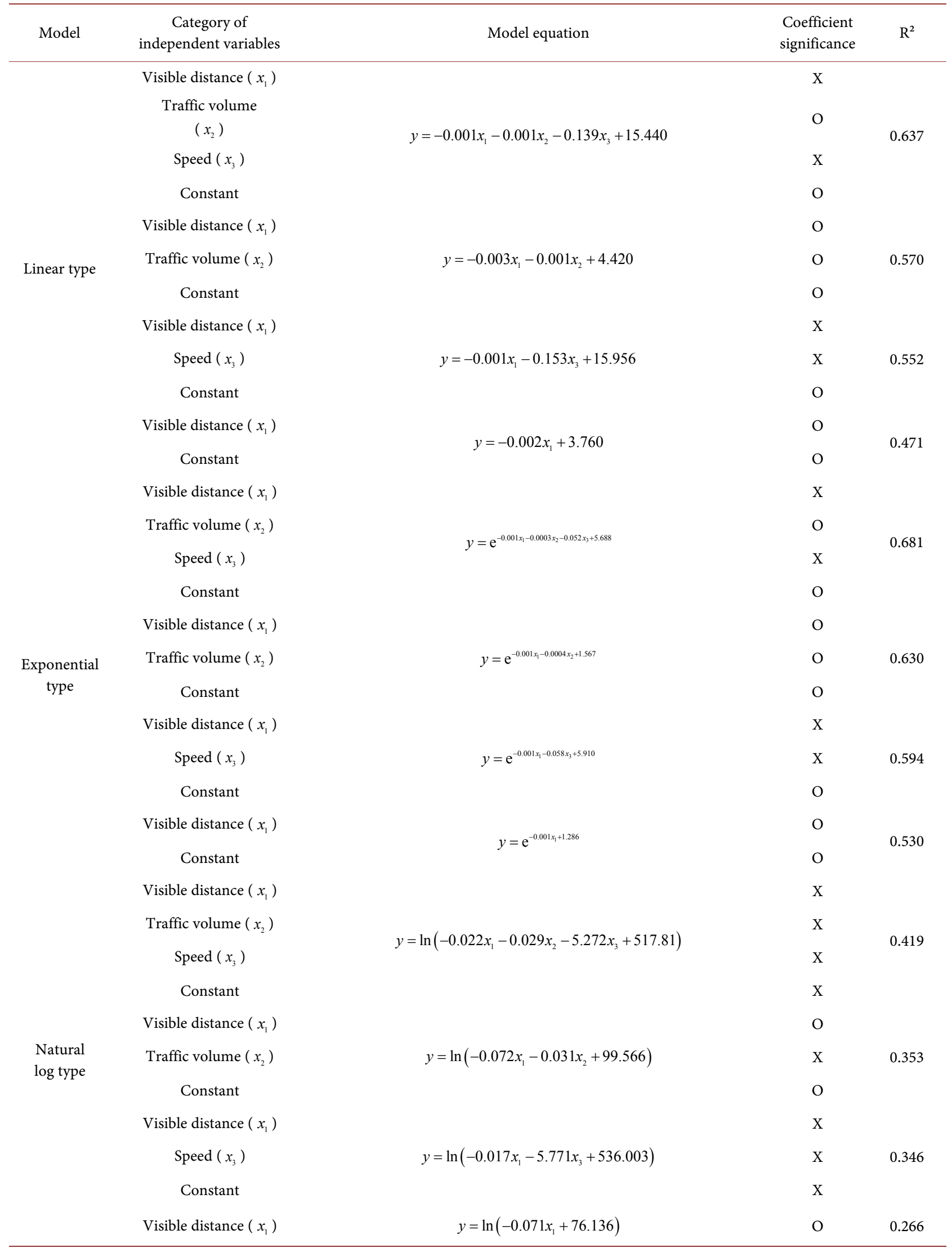




$$
y=\mathrm{e}^{-0.001 x_{1}-0.0004 x_{2}+1.567}
$$

where

$y$ : Risk index;

$x_{1}:$ Visible distance $(\mathrm{m})$;

$x_{2}$ : Traffic volume $(\mathrm{pcu} / \mathrm{h} / \mathrm{ln})$.

A risk level was derived in terms of the visible distance and the traffic volume through the risk index model equation. Based on $200 \mathrm{~m}$ of visible distance, which was analyzed to be significant enough to affect traffic flow, with the visible distance below $200 \mathrm{~m}$ being finely divided every $50 \mathrm{~m}$, the traffic volume was divided by $400 \mathrm{pcu} / \mathrm{h} / \mathrm{ln}$, when considering the time and the frequency of occurrence of fog. The risk indices derived through the risk index model equation are presented in Table 6. A traffic risk level at the time of the occurrence of fog with a traffic volume of $800 \mathrm{pcu} / \mathrm{h} / \mathrm{ln}$, which was the traffic volume at the time of a frequent occurrences of fog in the study, was more than $y$ twice as high with a $200 \mathrm{~m}$ visibility and approximately three times as with $50 \mathrm{~m}$ visibility as compared to that of a normal conditions. The above results are consistent with the study result of Park et al. [17], in which the risk impact index was 3.27 times higher during occurrences of fog, and the study result by the Korea Road Traffic Authority [1], in which the fatality rate was three times higher during occurrences of fog than that of normal conditions. Even with the same visibility, the risk level was higher as a traffic volume decreased, indicating that a traffic risk level increases with shorter visible distances and lower traffic volumes. The reason for this was because drivers did not change the vehicle speed often to maintain the gap with the vehicle in front of them when the traffic volume was maintained at a high level, whereas drivers changed vehicle speed rapidly without visible vehicles in front of them when the traffic volume was low (Figure 3).

\section{Conclusions}

Fog is a factor that degrades the visibility of drivers. It is a weather condition that can affect traffic flow, which induces traffic congestion and causes a higher risk of mass traffic accidents. Thus, this study developed a traffic risk index based on the analysis results on traffic characteristics during occurrences of fog. The conclusions of the study results are summarized as follows: This study derived the level of visible distance that affected traffic flow through the relationship of traffic volume, speed, and density according to the visible distance. The traffic volume decreased in most densities during occurrences of fog, as did the traffic speed at most volumes s. In particular, a significant difference in the traffic volume during occurrences of fog with less than $200 \mathrm{~m}$ of visibility was revealed as compared to that without fog, affecting changes in traffic flow. In addition, the deviation in speed was set to as a traffic risk level to develop the traffic risk index during occurrences of fog. An exponential model with independent variables set as the visible distance and the traffic volume using a regression model was proposed as the traffic risk index model. According to the calculated 
Table 6. Traffic risk index according to visible distance and traffic volume.

\begin{tabular}{|c|c|c|c|c|c|}
\hline \multirow{2}{*}{$\begin{array}{c}\text { Risk index } \\
\text { Visible distance }(\mathrm{m})\end{array}$} & \multicolumn{5}{|c|}{ Traffic volume (pcu/h/ln) } \\
\hline & 400 & 800 & 1200 & 1600 & 2000 \\
\hline 50 & 3.88 & 3.31 & 2.82 & 2.40 & 2.05 \\
\hline 100 & 3.70 & 3.15 & 2.68 & 2.29 & 1.95 \\
\hline 150 & 3.51 & 3.00 & 2.55 & 2.17 & 1.85 \\
\hline 200 & 3.34 & 2.85 & 2.43 & 2.07 & 1.76 \\
\hline 500 & 2.48 & 2.11 & 1.80 & 1.53 & 1.31 \\
\hline 1000 & 1.50 & 1.28 & 1.09 & 0.93 & 0.79 \\
\hline
\end{tabular}

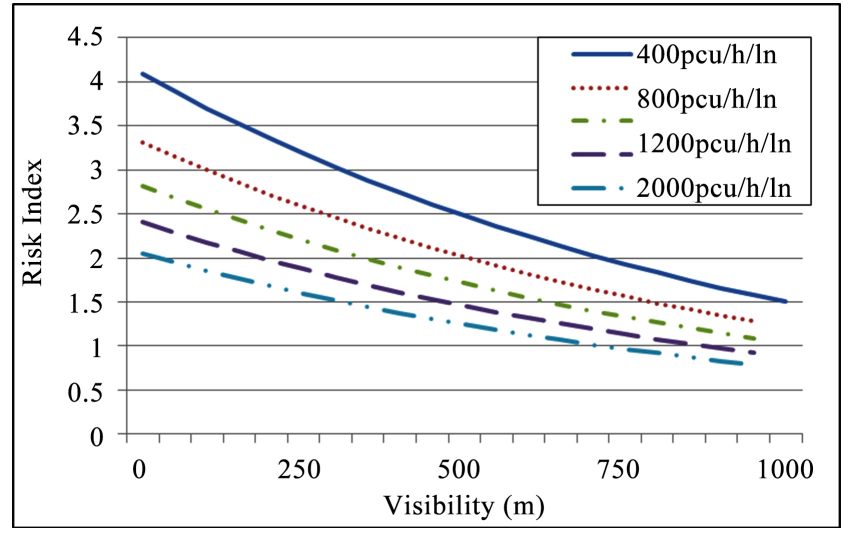

Figure 3. Traffic risk index model.

results using the study model, the traffic risk increased as the visible distance was shortened and the traffic volume was lower. The traffic risk level at a traffic volume level of $800 \mathrm{pcu} / \mathrm{h} / \mathrm{ln}$, which was the traffic volume level at the time of a frequent occurrence of fog in the study road section, was more than approximately twice as high at the time of the occurrence of fog with a $200 \mathrm{~m}$ visibility and approximately three times as high as an occurrence of fog with $50 \mathrm{~m}$ visibility as compared to that of a normal time.

The study results are expected to be utilized as foundational data to establish traffic management strategies that can minimize traffic congestion and reduce traffic accidents during occurrences of fog. If the visibility is less than $200 \mathrm{~m}$, the traffic operation manager can check the road condition (traffic volumes, speed limit and so on) and help to control the road to prevent traffic accidents. For examples, the manger can recommend to detours to drivers, control the speed limit by using the variable speed limits (VSL), and provide fog and road information to drivers through mobile phones or by radio. They are also expected to contribute to improvements on traffic safety by helping drivers to intuitively recognize levels of risk.

\section{Acknowledgements}

This study was supported by "2018 ITS Performance Evaluation Project" of the 
Korea Institute of Civil Engineering and Building Technology.

\section{References}

[1] Korea Road Traffic Authority (2014) Road Traffic Accidents Statistical Analysis in Korea, 2015.

[2] The Chosunilbo (2006) 11 Dead in Massive Pile-Up on Seohae Grand Bridge. http://english.chosun.com/site/data/html_dir/2006/10/03/2006100361015.html

[3] Hankyoreh (2018) The Cause of the Cloud's "Fog” Deaths and Delays. http://www.hani.co.kr/arti/science/science_general/837553.html

[4] The Busan ilbo (2015) 23 Injured in 43 Vehicle Crash on the Central Highway (What Caused the Accident). http://news20.busan.com/controller/newsController.jsp?newsId=20150116000174

[5] The Chosunilbo (2015) Hidden Heroes in 106 Car Crash on the Yonggiong Bridge. http://news.chosun.com/site/data/html_dir/2015/02/16/2015021600534.html?Dep0 $=$ twitter\&d=2015021600534

[6] Oh, J.S., Cho, D.S., Cho, Y. and Chung, J.H. (2002) A Study on the Variability of Driver's Speed in the Foggy Weather. Korean Society of Civil Engineers, 22, 677-685.

[7] Samsung Traffic Safety Research Institute, Travel Speed and Traffic Accident Analysis in Fog Road. Report, 2015.

[8] Abdel-Aty, M.A., Oloufa, A., Peng, Y., Shen, T.S., Yang, X. and Lee, J. (2014) Real Time Monitoring and Prediction of Reduced Visibility Events on Florida's Highways. University of Central Florida Report.

[9] Cho, H.J. and Yoon, S. (2002) Effects of Reduced Visibility Due to Fog on Traffic Flow. Conference of Korean Society of Civil Engineers, 11, 81-84.

[10] Broughton, K.L.M., Switzer, F. and Scott, D. (2007) Car Following Decisions under Three Visibility Conditions and Two Speeds Tested with a Driving Simulator. Accident Analysis and Prevention, 39, 106-116. https://doi.org/10.1016/j.aap.2006.06.009

[11] Son, Y. and Jeon, J.S. (2013) A Study on Traffic-Flow Characteristic Changes on Expressway by Visibility. The Journal of the Korea Institute of Intelligent Transport Systems, 12, 116-126. https://doi.org/10.12815/kits.2013.12.6.116

[12] Kim, S. and Lim, S.H. (2017) An Analysis of Change in Traffic Characteristics with Fog. The Journal of the Korea Institute of Intelligent Transport Systems, 16, 92-106. https://doi.org/10.12815/kits.2017.16.4.92

[13] Cho, H.J. (2003) Analysis of Hazardous Fog and Index Development in Korea. The Korean Geographical Society, 38, 478-489.

[14] Chandler, T. (1965) The Climate of London. Hutchinson, London.

[15] Korea Meteorological Administration. http://www.weather.go.kr

[16] Lim, C.H. (2007) A Study on the Safe Speed Estimation on Fog-Bound Roads. Master's Thesis, The University of Seoul, Seoul.

[17] Park, J.T., Hong, J.Y. and Lee, S.B. (2010) Development of Traffic Accident Safety Index under Different Weather Conditions. Journal of Korean Society of Transportation, 28, 157-163.

[18] Park, H.J., Joo, S.H. and Oh, C. (2014) Development of an Evaluation Index for Identifying Freeway Traffic Safety Based on Integrating RWIS and VDS Data. Journal of Korean Society of Transportation, 32, 441-451. 
https://doi.org/10.7470/jkst.2014.32.5.441

[19] Gyeonggi-Do Transportation Information Center. http://gits.gg.go.kr/web/board/2578.do

[20] Ministry of Land, Infrastructure and Transport (2013) Explanation of Rules about the Structure and Facility Standards of Road.

[21] Ministry of Land, Infrastructure and Transport (2015) 2014 Annual Report on Road Traffic Statistics.

[22] Lee, H.S. and Lim, J.H. (2011) SPSS 18.0 Manual. JypHyunJae Publishing Co.

[23] Garber, N.J. and Gadiraju, R. (1988) Speed Variance and Its Influence on Accidents. AAA Foundation for Traffic Safety.

[24] Lee, S., Lee, S.B., Kim, J.H. and Kim, J.W. (2007) Development of Model for Highway Design Consistency Evaluation. Proceedings of the KOR-KST Conference, 55, 306-314.

[25] Kim, S.Y. (2007) The Development of Safety Evaluation Criteria Based on Vehicle Speeds and Crash Data for Multi-Lane Highways. Doctor's Thesis, The University of Seoul, Seoul. 